\title{
The spatio-temporal patterns of urban-rural development transformation in China since 1990
}

\author{
Yanfei Wang ${ }^{\text {a, b, *, Yansui Liu }}{ }^{\text {a, c, **, Yuheng Li }}{ }^{\text {a }}$, Tingting Li ${ }^{\text {a, b }}$ \\ a Institute of Geographic Sciences and Natural Resources Research, Chinese Academy of Sciences, Beijing 100101, China \\ ${ }^{\mathrm{b}}$ University of Chinese Academy of Sciences, Beijing 100049, China \\ c College of Resources Science and Technology, Beijing Normal University, Beijing 100875, China
}

\section{A R T I C L E I N F O}

\section{Article history:}

Received 16 July 2015

Received in revised form

5 November 2015

Accepted 13 November 2015

Available online 7 December 2015

\section{Keywords:}

Urban-rural development transformation

Urbanization

Urban-rural integration

Spatial pattern

China

\begin{abstract}
A B S T R A C T
China has undergone a dramatic transition echoed the unprecedented urbanization and economic growth since the late 1970s. The current research on urbanization has overlooked the transformation consistency between urban and rural areas. Although the Chinese central government has focused on improving rural residents' livelihood, it is still far from achieving coordinated urban-rural development. This paper provides a comprehensive assessment of China's urban-rural development transformation (URDT) based on three indicator systems, namely the urban-rural development level (URDL), the urban -rural structure level (URSL), and the urban-rural coordination level (URCL). Findings from this investigation show that universal and intense URDT has taken place in China over the last two decades. This has been accompanied by growth of URDL and URSL and deterioration of URCL. There are, however, obvious spatial disparities in the different aspects of URDT. The western and northeastern regions of China have experienced slower transformation than other regions between 1990 and 2010. Correlation analysis among the sub-index shows that coordinated urban-rural development needs a certain initial socioeconomic level and moderate changes of URDL and URSL. This paper suggests that more attentions should be paid to rural areas and lagging areas in central and western China. Given the regional disparities of URDT, the most effective way to achieve urban-rural integration in China is by taking the overall considerations of development policies of both region and urban-rural areas aimed at various urban-rural development transformation characteristics.
\end{abstract}

(๑) 2015 Elsevier Ltd. All rights reserved.

\section{Introduction}

It has been recognized that urban-rural interactions exit in the form of mutual linkages (population, goods, capital and information), and sector linkages manifesting rural activities that take place in cities and activities that are usually classified as urban taking place in the rural areas (Tacoli, 1998). These linkages and a hybrid form of spatial complex have blurred the rural-urban division such as the existence of "desakota" in the Asian context (McGee, 1989). In some other empirical investigations, three space models produced by urban-rural interaction have been deployed, i.e., cityregions, exurbia, and 'urbanization' in the countryside

\footnotetext{
* Corresponding author. Institute of Geographic Sciences and Natural Resources Research, Chinese Academy of Sciences, Beijing 100101, China.

** Corresponding author. Institute of Geographic Sciences and Natural Resources Research, Chinese Academy of Sciences, Beijing 100101, China.

E-mail addresses: wangyf.13b@igsnrr.ac.cn (Y. Wang), Liuys@igsnrr.ac.cn (Y. Liu).
}

accompanied by 'ruralization' in the city (Woods, 2009). Though these interactions play vital role in promoting urban-rural development, the spatial structure and effects from different scales of global forces, the state and local agent make different urban-rural societal transformations (Antrop, 2004; McGee, 2008; Tacoli, 1998).

Being a traditional agricultural country of strong rural roots, China has been experiencing economic, social and institutional transformations (Liu, Lu, \& Chen, 2013; Long, Zou, Pykett, \& Li, 2011). Between 1958 and 1978, urban and rural socioeconomic systems were totally independent in China. The linkages between urban and rural areas were severely controlled. During the so called centrally planned era, population movement was forbidden except few means of studying, marriage etc., and the prices of agricultural products were underestimated. Since the reform and opening up in 1978, rural development in China has been promoted by the introduction of the household responsibility system and the development of township enterprises. Particularly, after the famous speech addressed by Deng Xiaoping in the south of China in 1992, 
the Chinese government accelerated the urban development and the construction of industrial zones (Wei, 2015). The institutional reforms including the establishment of the socialist market economy and the loose of migration policy have largely promoted free flow of production factors. The changing institutional roles have strengthened urban-rural interaction and linkage under different situation of urban-rural development as well (Li \& Hu, 2015). We also witnessed a large volume of migration from rural to urban areas in China during the transition period. The total number of migrants was estimated to be 230 million in 2011, 80\% of whom were from rural background (Wang \& Fan, 2012). According to China's National New urbanization plan, China's urbanization ratio will reach $60 \%$ by 2020 , indicating that there will be more than 13.6 million people migrating from rural areas to urban areas every year.

Generally, urban and rural areas in post-reform China have been experiencing dramatic transformation across a range of indicators such as population migration, land use and landscape changes, economic growth and living style (Chen, Zhang, Liu, \& Zhang, 2014; Li, Chen, Wang, \& Liu, 2014; Liu, Kuang et al., 2014; Li, Li, Hans, \& Liu, 2015; Li, Long, Liu, \& Tu, 2015; Li, Zhang, Hans, \& Liu, 2015; Lin, 2007; Long, Liu, Hou, Li, \& Li, 2014; Siciliano, 2012). These transformations have dramatically changed the urban-rural territory system, and posed challenges to urban-rural integrated development. And scholars have paid considerable attentions on the issues of urban-rural disparity, urban-rural conflicts and rural hollowing (Li, Zhang, \& Liu, 2013; Liu, Liu, Chen, \& Long, 2010; Terry, Yue, Vjörn, \& Li, 2007; Yu, Wu, Zheng, Zhang, \& Shen, 2014). However, more work is still needed to examine and understand the status and dynamic of urban-rural relationship in transitional China. What is the spatio-temporal pattern of the urban-rural development transformation? How should we assess this transformation? This paper attempts to investigate the urban-rural development transformation (URDT), its spatial patterns in China and urban-rural development policies with respect to different spatial patterns as well. Specifically, the aims of this paper are: (1) to construct a conceptual framework and to establish indicator systems that can measure URDT in China; (2) to analyze the spatiotemporal characteristics and internal relationships of China's URDT; and (3) to discuss some of the major policy implications for achieving coordinated urban-rural development.

\section{Research base: urban-rural development transformation}

Transformation can be defined as a gradual, continuous process of societal change where the structural character of society (or a complex sub-system of society) transforms (Martins \& Romans, 2005). China is in an era of fast transformation in which its urban-rural territorial system undergoes changes related to its regional society, economy, institution and its effects on environment. The urban-rural development transformation (URDT) can be defined as the ongoing process of urban-rural factors flow, structure change and development mechanism transformation. This highlights a transition from isolated socioeconomic structures towards a more coordinated development between urban and rural areas (Liu, Hu, \& Li, 2014). URDT is facilitated and accelerated by population urbanization, economic growth, capital accumulation and government management. Economic growth and social economic change promote factors flow and gather and structural changes between urban and rural areas which also lead to urban-rural sector interaction. These forces make impact on the changes of urban-rural development relationship (Fig. 1).

Economic growth has promoted urban expansion and rural population flow in the industrial society; this reconstructs the urban-rural territorial system. The obvious characteristics are the transformation of industry structure and employment structure, companied with changes of the space form and landscape. The dualistic model explained economic growth and stated a sector explanation of urban-rural relations (Lewis, 1954; Todaro, 1969). With the surplus rural laborers moving from the traditional rural subsistence sector to a modern urban industrial sector in the developing countries, the equilibrium between urban and rural society would be achieved. However, urban-rural contrast studies triggered debates focused on the resource allocation between agriculture and industry, or the urban and rural sector, and between urban and rural policies (Douglass, 1998; Lipton, 1993). The division of urban-rural management and the control on factor flows lead to partial transformation in China, and the urban-biased policy has been shown to be detrimental for a healthy relationship between urban and rural China (Li \& Hu, 2015; Li, Wang, Zhu, \& Zhao, 2014). We hold that urban and rural areas should develop equally in the transitional progress.

The research on URDT is centered on the dynamic of urban-rural relationship and its social economy. In this paper, URDT in urban-rural territorial system is categorized into socioeconomic growth, structural changes and relationship transition. Its assessment involves three major components: the development status of distinctive region; the urban-rural structural level, such as industry, social and consumption structures; and the condition of a coordinated urban-rural relationship. URDT appraisal is diagnosed from changes of three aspects in a given region: the urban-rural development level (URDL); the urban-rural structure level (URSL), and the urban-rural coordination level (URCL).

The URDL reflects regional economic and social conditions, which are not only the former base, offering the possibility for urban-rural development transformation, but also a new condition for the latter development. The URSL reflects the structures of population, industry, employment and land use, which represents the inner spatial pattern and its functionality in the urban-rural region. The urban-rural structure suitable to corresponding economic level shows a good transformation. On the contrary, in many developing countries of Africa, Asia and Central and South American, excessive people clustering and unlimited spread of cities without strong economic growth brought serious city disease. The URCL reflects the ability and status of integrating urban-rural development, and integrated effects of regional resources allocated to urban and rural areas. URCL is a comprehensive evaluation of whether the urban-rural relationship is better or not (Long et al., 2011). We assume that when URDL is relatively low, urban-rural development lacks sufficient motivation to transform and its structure and disparity change slowly; and when URDL gradually increases, the urban-rural development creates a stage of fast transformation. This would result in economic society, consumption and urban-rural structures to rapidly change and urban areas to become intensive and complex features. However, if there is a lack of suitable strategies, policies and planning to promote rural development, URCL would diminish due to the rural brain drain, infrastructure deficiencies, lack of funds and low education levels in the rural areas. When URDL is at a high level, urban-rural development would be in a stabilization process, with a low rate of change for the urban-rural social economy and its structures, and it would have closer linkages to fulfill people's demand such as for rural amenity and rural lifestyles.

\section{Research methodology and data}

\subsection{Index system of the evaluation of URDT}

URDT can be measured from three aspects including URDL, URSL and URCL. The indicator systems corresponding to each aspect were established to enable comprehensive assessment. The indicator 


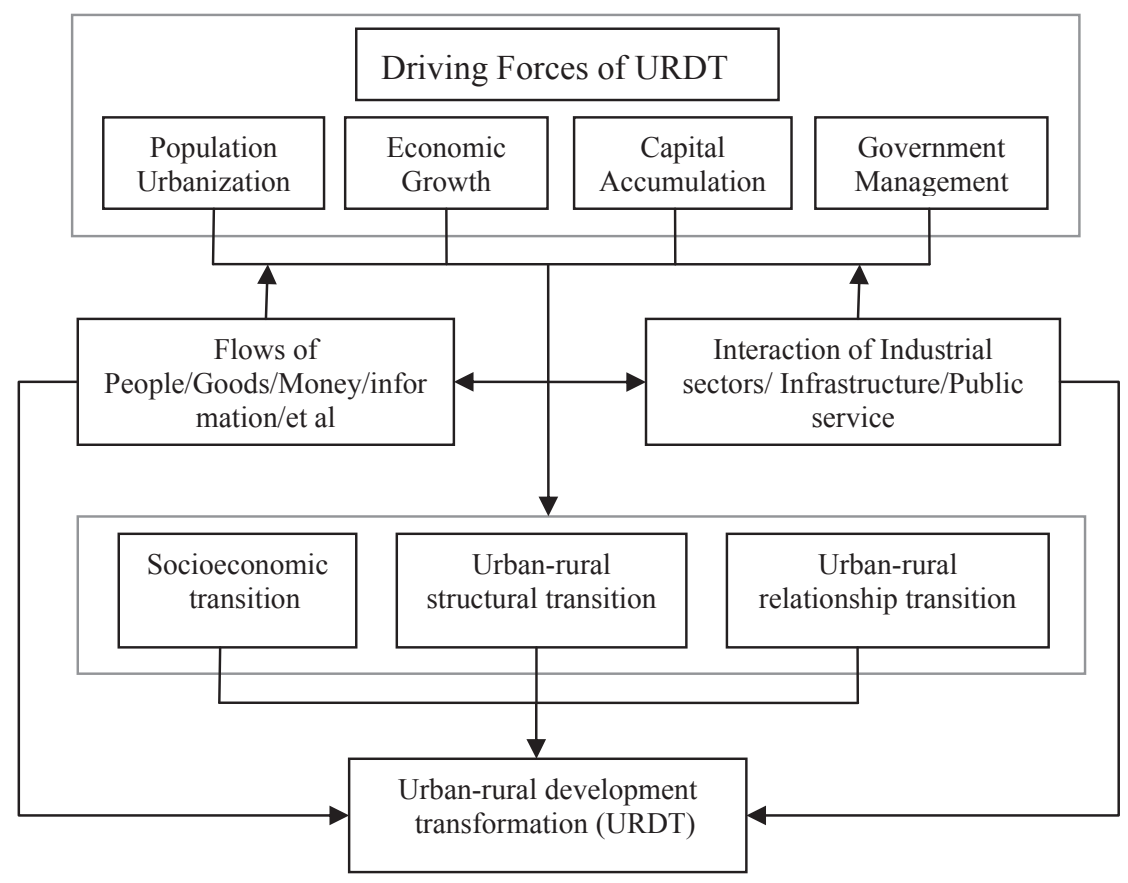

Fig. 1. Analytical framework to urban-rural development transformation in China.

system in Table 1 reflects the condition of urban-rural development transformation and a $\triangle$ URDL denotes the changes of the urban-rural economy, society, culture and environment. We chose economic development, urban-rural livelihood and infrastructure, and social service as rule layer factors which were composed of five factors. All these factors have expected positive effects on URDL. URSL is the urban-rural structural ratio corresponding to the progress of industrialization and urbanization, and four indicators were chosen which stand for structures of urban-rural industry, employment, urbanization and built-up land use (Table 2). $\triangle$ URSL reflects the changes of urban-rural structures. URCL is the result and effect of growth of URDL and URSL influenced by micro development strategy and urban-rural institution. $\triangle U R C L$ reflects the changes of the urban-rural relationship. To measure the degree of URCL, we chose the general indicators of economy and society between urban and rural areas (Table 3 ).

\subsection{Data sources}

Data for the indicators shown in Tables 1-3 refers to the China's Statistical Yearbooks in various years, China's Census Year books, China's Regional Statistic Yearbooks and the Provincial Statistics. The data of population and employment is from China's census year book. The data of urban and rural construction land are obtained from the Chinese Data Sharing Infrastructure of Earth System Science. The prefecture-level city is the basic research unit, excluded cities in Taiwan, HongKong, and Macao. And cities in Tibet and Qinghai are represented by the provincial data due to the lack of corresponding statistic data. Thus, there are 337 study units. According to our aforementioned aim, we ensured that the data used were unified and that the economic data was based on comparable pricing.

\subsection{Assessment of URDT}

Generally, factor flows and agglomeration between urban and rural areas involve complex progress, which promotes urban-rural spatial restructuring and economic structural changes. Lin (2001) identified the spatial transformation in the Pearl River Delta in China by quantifying selected variables of urban-rural linkages. Base on urban-rural linkage, Li, Zhang, and Liu (2013) assessed the level of integrated urban-rural development at the province level in China. Liu, Hu, and Li (2014) evaluated the urban-rural development transformation in the Bohai rim of China from the aspects of population, land, industry and society. In transitional China, while urban-rural territorial system exhibit dramatic development, there is enlarged disparity between urban and rural areas and different spatial patterns. The multi-dimensional characteristics and implications for policy-making affecting urban-rural development are beyond the scope of socioeconomic changes and urban-rural interaction assessment.

This study uses an entropy method to assess the URDT. All the indicators in the assessment system were positive for the subsystem. To make the various indicators comparable, we used Equation (1) to transform the indicators into comparable common units by normalizing all measures and ranging the values from 0 to 1 . To

Table 1

Indicator system for the urban-rural development level (URDL) assessment.

\begin{tabular}{|c|c|c|}
\hline Rule layer factors (weight) & Indicator layer factors (weight) & Definition \\
\hline Economic development (0.253) & GDP per capita ( 1$)$ & Gross domestic product per capita \\
\hline \multirow[t]{2}{*}{ Urban-rural livelihood (0.483) } & Rural income level (0.861) & Rural per capita net income \\
\hline & Urban income level (0.139) & Urban per capita disposal income \\
\hline \multirow[t]{2}{*}{ Infrastructure and social service $(0.264)$} & Education level (0.495) & Average education attainment \\
\hline & Medical level (0.505) & The number of hospital beds per 1000 people \\
\hline
\end{tabular}


Table 2

Indicator system for the urban-rural structures level (URSL) assessment.

\begin{tabular}{|c|c|c|}
\hline Rule layer factors (weight) & Indicator layer factors (weight) & Definition \\
\hline Urban share $(0.264)$ & UP/TP & $\mathrm{UP}=$ the urban population; $\mathrm{TP}=$ the total population \\
\hline Employment structure (0.295) & $\mathrm{NAE} / \mathrm{TE}$ & $\mathrm{NAE}=$ none-agriculture employment; $\mathrm{TE}=$ total employment \\
\hline Industrial structure $(0.224)$ & STIO/GDP & $\mathrm{STIO}=$ the second and third industry output; GDP = gross domestic product \\
\hline Ratio of urban built land (0.217) & UBL/TBL & $\mathrm{UBL}=$ the urban construction land; URBL $=$ the sum of urban and rural build construction land \\
\hline
\end{tabular}

Table 3

Indicator system for the urban-rural coordination level (URCL) assessment.

\begin{tabular}{|c|c|}
\hline Rule layer factors (weight) & Definition \\
\hline Urban-rural income gap (0.373) & Dividing the rural per capita net income by the urban per capita disposable income \\
\hline Urban-rural consumption comparison $(0.235)$ & Dividing the rural consumption expenditure per capita by urban expenditure consumption per capita \\
\hline Industrial labor productivity disparity (0.392) & Dividing the productivity per capita in the first industry by that in the other industries \\
\hline
\end{tabular}

determine the weights for the indicators, the subjective weighting method and the objective weighting method are commonly used. The entropy method is one of the objective weighting methods. This method uses the information of original data, and it can eliminate the subjective preference of the valuators. The information entropy is the key in the entropy method. In general, the higher the information entropy is, the more balanced the system is, and eventually, the smaller the weight is (Zou, Yun, \& Sun, 2006). In this paper, we used the entropy method to determine the weight of the indicators, and to apply a weighted summation method to calculate the comprehensive value of URDL, URSL, and URCL, according to Equation (2).

$X_{i j}^{\prime}=\left(X_{i j}-\min \left(X_{j}\right)\right) /\left(\max \left(X_{j}\right)-\min \left(X_{j}\right)\right)$

$F_{i}=\sum_{j=1}^{n} w_{j} \times X_{i j}^{\prime}$

where $X_{i j}$ is the original value of indicator $j$ in the province $i$; $\min \left(X_{j}\right)$, and $\max \left(X_{j}\right)$ express the minimum and the maximum of the indicator $j$ respectively; $X_{i j}^{\prime}$ is the standardized value of the indicator; $n$ is the number of indicators; $w_{j}$ is the weight of the indicator $j ; F_{i}$ is the calculated values of province $i$ that stand for URDL, URSL and URCL.

\section{Results}

\subsection{The spatial patterns of China's URDL, URSL and URCL}

Economic reform such as decentralization, marketization and globalization has triggered regional development in China ( $\mathrm{Li}, \mathrm{Li}$ et al., 2015; Wei, 2001). According to the development paths, there were two stages with different transformation characteristics. In the first stage, the township enterprises have played a vital role under the dual-track economic system, which has promoted rural urbanization of small towns. In the later stage, the urbanization of a city-based and land-centered progress accelerated the gathering trend of urban-rural space after the mid-1990s (Lin, 2007). During this process, urban-rural development experienced dramatic transformation (Table 4). China has achieved fast economic growth at an annual average rate of $9.08 \%$ per capita GDP between 1990 and 2010, accompanied by which resident livelihood and public services got continuous improved. With the increase of URDL, population urbanization and urban expansion change the urban-rural structures except for the dynamic of industrial structure and labor employment. The proportion of urban population increased from $26.41 \%$ to $49.95 \%$ between 1990 and 2010 when a higher number of rural people migrated to urban areas. Urban build-up area expanded by $6.3 \%$ every year, $1407 \mathrm{~km}^{2}$ per year, from 1990 to 2010 . However, the development between urban and rural areas is unbalanced. The income gap increased from 2.2 to 3.23 between 1990 and 2010, and the disparity of urban-rural productivity and consumption were huge.

To analyze the spatial patterns of URDT, the spatial characteristics of URDL, URSL and URCL divided into five grades by the method of Natural breaks in ArcGIS were highlighted in Fig. 2. The region with higher value of URDL and URSL suggests that it advances the dynamic of urban-rural development than other areas. The region with higher value of URCL has more balanced urban-rural development no matter whether it is developed or not. Constrained by physical conditions and general socioeconomic development, there are different spatial patterns among the subindexes, although some regions have relative consistency of their values. The URDL presents an agglomerating pattern. The highest values are mainly distributed in the coastal areas such as Yangtze Delta region, the Pearl River Delta, the Bohai Rim, and those large inland cities. The lowest values are mainly located in central and western China, especially the southwestern China such as Yunnan, Guangxi, Qinghai, and Gansu provinces. The URSL has a similar spatial pattern to the URDL. Compared with URDL and URSL, URCL has a different spatial pattern. The highest values are in southeastern China and the north provinces of Heilongjiang and Xinjiang, and the lowest values are in southwestern China.

There was obvious regional disparity in China especially after the reform and opening up (Fujita \& Hu, 2001). The transition progress of decentralization, marketization and globalization brought the East China ahead of other regions (Wei, 2001). According to Chinese statistic definition, there are four parts, which are eastern China, central China, western China and northeastern China. To coordinate regional development and narrow regional discrepancies, the central government has successively released the "Western Development Program", "Reviving Northeastern Region”, and "The Rising of Central China" on the back of state-led investment and policy which contrasts the measures of some coastal cities and special economic zones in 1980s and 1990s. However, the interregional inequality has been rising (Li \& Wei, 2010). According to the distribution of the sub-index of URDT, the four regions take on different situation of urban-rural development transformation (Table 5).

Eastern China, having the advantages of a predominant physical environment, an optimal location and a socioeconomic foundation is benefited from preference policies as the earliest areas to be opened up. The development of township enterprises brought the transition of rural areas, characterized by the transfer of employment and industrialization (Long, Zou, \& Liu, 2009). Due to the 
Table 4

Main indicators for the index of 1990, 1995, 2000, 2005 and 2010.

\begin{tabular}{|c|c|c|c|c|c|}
\hline Indicator type & 1990 & 1995 & 2000 & 2005 & 2010 \\
\hline GDP per capita (RMB) & 1644 & 2761 & 3987 & 6150 & 10,196 \\
\hline Urban income level (RMB) & 1510 & 2213 & 2925 & 4630 & 7358 \\
\hline Rural income level (RMB) & 686 & 846 & 1066 & 1377 & 2104 \\
\hline Education level (year) & 6.32 & 6.81 & 7.67 & 7.95 & 8.50 \\
\hline Medical level (hospital beds per 1000 persons) & 2.55 & 2.59 & 2.51 & 2.57 & 3.56 \\
\hline Urbanization rate $(\%)$ & 26.41 & 29.04 & 36.22 & 42.99 & 49.95 \\
\hline Employment structure (\%) & 39.90 & 47.80 & 50.00 & 55.20 & 63.30 \\
\hline Industrial structure (\%) & 72.88 & 80.04 & 84.94 & 87.88 & 89.90 \\
\hline Ratio of urban built land (\%) & 17.00 & - & 20.46 & - & 31.00 \\
\hline Urban-rural income gap & 2.20 & 2.71 & 2.79 & 3.22 & 3.23 \\
\hline Urban-rural consumption comparison & 2.19 & 2.70 & 2.99 & 3.28 & 3.07 \\
\hline Industrial labor productivity disparity & 4.05 & 4.38 & 5.64 & 5.88 & 5.16 \\
\hline
\end{tabular}

Note: The economic data using the comparable price from 1990.

effects of problems of rural enterprise institution and environment and the transition of urban industries, urban area expanded and reasserted its leader status. The urban-rural interaction and linkage of migration from rural to urban and the transfer of agricultural technology promoted the territorial transformation. As a consequence, the eastern China possesses higher value of URDL and URSL than other regions in 2010 compared with 1990. Central China is historically the major grain production area. It possesses excellent crop production conditions such as favorable agro-climatic conditions, agricultural machinery, irrigated facilities and traditional agrarian culture. It has unique geographical advantages as transport hub of north-south railway and Yangtze River. However, compared with eastern China, it doesn't take supporting policies from central government and competitive advantages under marketization and globalization. URDT therefore experienced a slower rate of urbanization and the development of rural industry.

Northeastern China had the highest value of URDL, URSL, and URCL in 1990. It used to be the most important industry base for China's industry construction. However, it has lagged behind the rest of the country in the reform and open-up due to the transition of heavy industry and planed economic institution (Zhang, 2008). The rural area in this region has twice arable land per capita than average level of China and forms one of the most important commodity grain bases. However, it has a lower self-development capability due to a lack of commercial crops and agricultural processing.

The URDL, URSL and URCL of Western China are the lowest. The poorer regions of China are clustered in this area and only few large cities and regions with energy and mineral products are relatively developed. These regions fall behind the other regions because of a frangible ecological environment, a backward transportation system, adverse location conditions and the low efficiency of capital use. Furthermore, financial deficit and inadequate technologies weaken sustainable development and make it hard for equal public services between urban and rural areas. In many regions of West China, therefore, the problems of industry upgrading and urbanization are referred to not only regions but also urban and rural areas. The disparity between urban and rural areas here is the largest.

\subsection{The dynamic changes of URDL, URSL, and URCL between 1990 and 2010}

Fast industrialization, urbanization, and accelerated globalization have driven the changes of China's urban-rural territorial system. This consists of the main characteristics of URDT between 1990 and 2010. According to the calculated values, the changes of URDL, URSL and URCL represented by $\triangle \mathrm{URDL}, \triangle \mathrm{URSL}$ and $\triangle \mathrm{URCL}$ were mapped respectively (Fig. 3).
URDL increased across China between 1990 and 2010 and the increase occurred on a spatial agglomeration. The higher values cluster in two belt areas. One area is the coastal economic belt, such as Tianjin, Beijing, Jiangsu, Guangzhou, and Shanghai; the other belt area is in the north, predominantly located in the Inner Mongolia province. The lower values are mainly distributed in western and central China. Thus, eastern China, making more substantial growth, has tended to enlarge the regional socioeconomic disparity since 1990.

China's urban-rural structures have rapidly changed under accelerating urbanization and relevant policy adjustment. The urban characteristics have been dominant with population spatial clustering and urban sprawl. From 2000 to 2010, according to the Chinese Statistical Yearbook, the urban built-up land area in China grew by $78.5 \%$, and the urban population increased by $46 \%$. However, factor flow and urban expansion exhibit spatial disparity in China (Liu, Fang, \& Li et al., 2014; Liu, Hu et al., 2014; Liu, Kuang et al., 2014). In terms of the $\Delta$ URSL, the higher values are mainly distributed in the coastal provinces such as Shandong, Jiangsu, Zhejiang and Guangdong, and the areas along the Yangtze River. The lower values are located in northeastern and northwestern China. Different from backward regions, some developed cities such as Beijing, Tianjin and Shanghai take slow urban-rural structure changes because of the higher initial ratio of urban population and nonagricultural output and employment.

Unfortunately, unbalanced development between urban and rural areas has enlarged urban-rural disparity. The URCL value of $62.7 \%$ of prefectural-level cities declined from 1990 to 2010. $\Delta$ URCL takes on a complex spatial pattern. The higher value scatters over a wide area, while the lower value distributes in areas possessing abundant energy and mineral resources such as Inner Mongolia, Shanxi and Jilin, and in a few developed economic regions such as Beijing, Tianjin, and Shanghai.

In order to identify the characteristics of spatial heterogeneity of $\triangle$ URDL, $\triangle$ URSL and $\triangle$ URCL, Getis-Ord Gi* analysis used to study local pattern in spatial data (Ord \& Getis, 1995), was undertaken on Arc-Toolbox of ArcGIS. The Getis-Ord Gi* maps of URDT index between 1990 and 2010 are shown in Fig. 4. The hot spot areas of $\triangle$ URDL are mainly distributed in the Pearl River Delta, the Yangzi River Delta and the Bohai Sea Rim, three groups of cities in China. The cold spots cluster in southwestern China, in the Qinghai-Tibet Plateau and the Yunnan-Guizhou Plateau. The spatial patterns of hot and cold areas of $\Delta$ URSL are consistent with the distribution of its lower and higher value, as shown in Fig. 3. In terms of $\Delta U R C L$, the hot spot areas with obviously increasing URCL distribute in northern Jiangsu, Anhui and adjacent areas between Sichuan and Chongqing, while the cold areas mainly distribute in Inner Mongolia, Jilin and Tibet. 

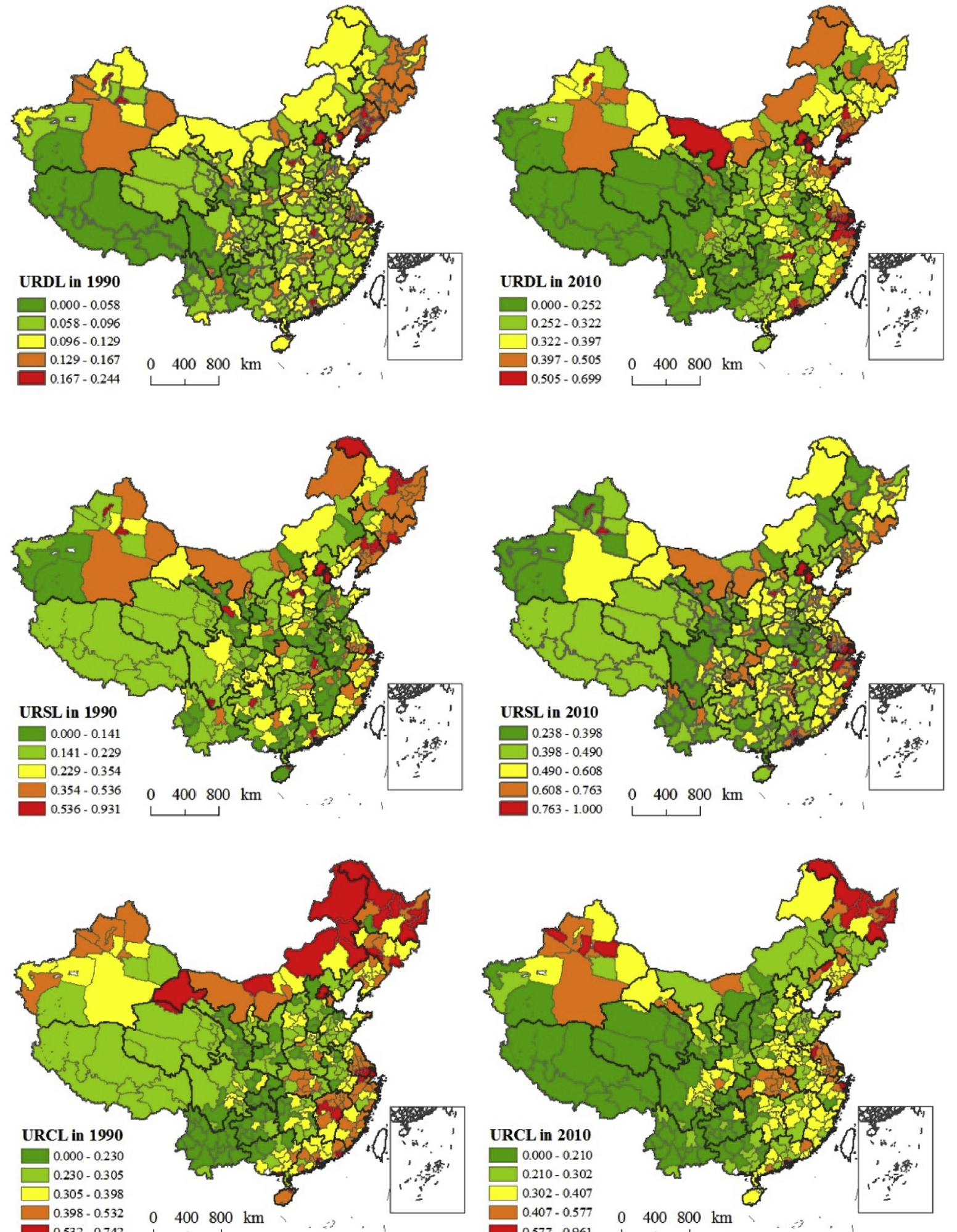

Fig. 2. The spatial patterns of URDL, URSL, and URCL in 1990 and 2010.

\subsection{The mutual correlation among the subsystems of URDT}

China is currently in stage of accelerating development, thus its urban-rural development transformation is inevitable. However, socioeconomic level, structures and urban-rural coordination are not always consistent. To explore the correlation between the sub-system of URDT, three aspects were taken into consideration, the correlation among the subsystem, the correlation between the changes of subsystem from 1990 to 2010 shown in scatter graphs and the correlation between the initial development condition and the changes. 
Table 5

The statistical features of URDT in different regions of China.

\begin{tabular}{|c|c|c|c|c|c|c|}
\hline \multirow[t]{3}{*}{ Region } & \multicolumn{6}{|l|}{ Index } \\
\hline & \multicolumn{3}{|l|}{1990} & \multicolumn{3}{|l|}{2010} \\
\hline & URDL & URSL & URCL & URDL & URSL & URCL \\
\hline Eastern China & 0.116 & 0.295 & 0.388 & 0.411 & 0.621 & 0.363 \\
\hline Central China & 0.109 & 0.236 & 0.323 & 0.318 & 0.530 & 0.309 \\
\hline Western China & 0.088 & 0.239 & 0.293 & 0.282 & 0.470 & 0.243 \\
\hline Northeastern China & 0.143 & 0.412 & 0.464 & 0.386 & 0.544 & 0.453 \\
\hline
\end{tabular}

Both the linear ascending trend and the high correlation suggest that there is a consistency between URDL and URSL in both 1990 $\left(R^{2}=0.677\right)$ and $2010\left(R^{2}=0.637\right)$ (Fig. 5). On the one hand, economic and social development is the initial power for rural factors flowing to urban areas and urban expansion whilst, on the other hand, the effect of population concentration and industry cluster helps stimulate URDL. However, the correlation between URCL, URDL and URSL is much lower. URCL is more related to URDL $\left(R^{2}=0.233\right.$ in 1990 and $R^{2}=0.250$ in 2010$)$ compared to URSL
$\left(R^{2}=0.150\right.$ in 1990 and $R^{2}=0.072$ in 2010). This means that the level of economic society has more effects on urban-rural integration than its structures. In China, accelerating urbanization of city expansion, population cluster and industrial adjustment may not lead to coordinated urban-rural development because of the dual urban-rural management and land-centered urbanization. According to correlation analysis, the correlation among $\triangle U R D L$, $\triangle$ URSL and $\triangle$ URCL are not significant (Fig. 6). This reflects the inconsistency within the changes of the subsystem.

The socioeconomic level is the prerequisite of the urban-rural development transformation. To distinguish the internal mechanism between the initial condition and the changes of a subsystem from the miscellaneous assessment results, we classified the initial URDL into six grades, based on their mathematical statistical features. Table 6 shows that the area with a higher initial value of URDL, has an obvious tendency to increase faster in economic society. It can be seen that there is also a path-dependence based on previous reform policies and location advantage. The value of $\triangle$ URSL is higher in lower socioeconomic regions, that is, these regions have experienced much faster population urbanization and

Table 6

The statistical features and interrelationships of China's URDT between 1990 and 2010.

\begin{tabular}{|c|c|c|c|c|c|}
\hline Initial URDL grade & Average $\triangle \mathrm{URDL}$ & Average $\triangle$ URSL & Average $\triangle \mathrm{URCL}$ & $\begin{array}{l}\text { Proportion of URCL growth units } \\
\text { in the total units of the same grade }\end{array}$ & Total units of the same grade \\
\hline$<0.05$ & 0.157 & 0.259 & -0.075 & $26.30 \%$ & 19 \\
\hline $0.05-0.075$ & 0.176 & 0.268 & -0.019 & $29.60 \%$ & 54 \\
\hline $0.075-0.10$ & 0.210 & 0.288 & 0.001 & $48.10 \%$ & 77 \\
\hline $0.10-0.125$ & 0.234 & 0.280 & -0.045 & $37.80 \%$ & 90 \\
\hline $0.125-0.15$ & 0.267 & 0.236 & -0.021 & $39.60 \%$ & 53 \\
\hline$>0.15$ & 0.307 & 0.192 & -0.064 & $27.90 \%$ & 43 \\
\hline
\end{tabular}
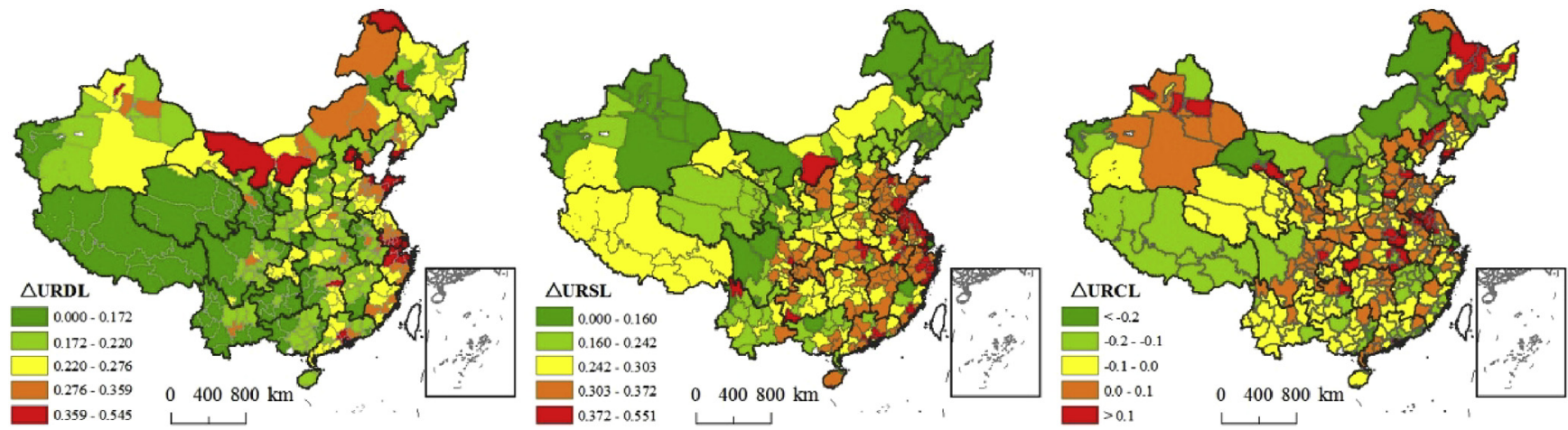

Fig. 3. The dynamic spatial patterns of China's urban-rural development transformation (URDT) between 1990 and 2010.
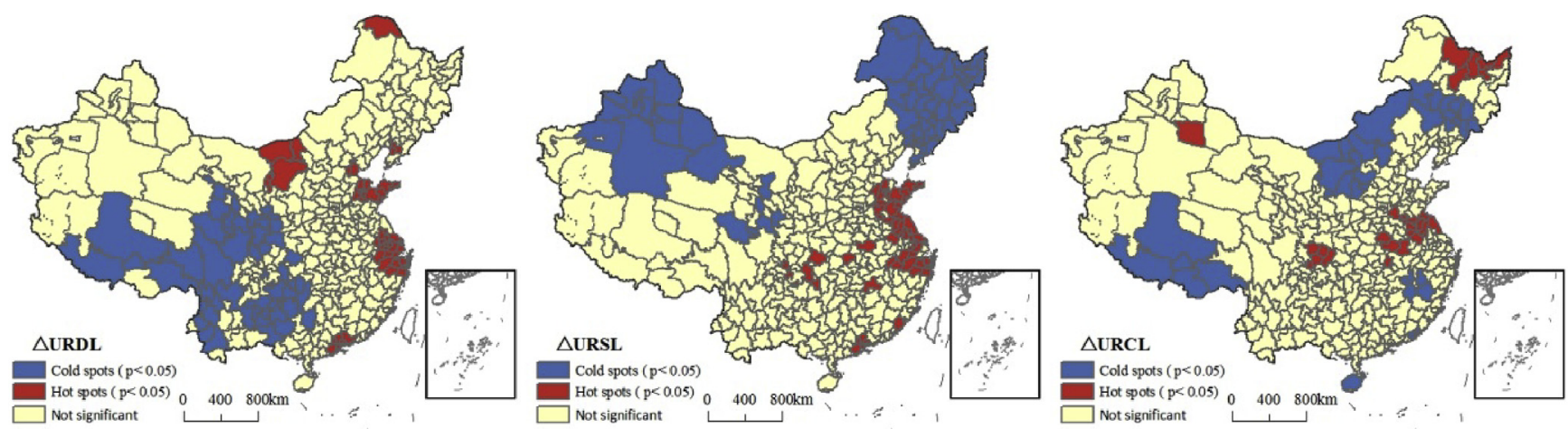

Fig. 4. Getis-Ord Gi* of local spatial characteristics of URDT between 1990 and 2010. 
industrial transition because of the lower initial socioeconomic conditions. The average value of $\triangle U R C L$ and its growth proportion takes on a declining trend from the third grade to not only the first grade, but also the sixth grade.

Stepping into the accelerating stage of urbanization with relaxation of the household registration, rural china has been confronting the rural brain-drain and deficient finance. In many developed areas, as the transfer of urban industry and the need for service industry in rural areas, such rural areas make much faster transition. However, rural development and institution innovation fall behind fast industrialization and urbanization in China (Long et al., 2011). According to the result in Table 6, the areas with adequate initial socioeconomic level and fast structural change have the highest ratio of positive $\triangle U R C L$. The area with the highest or the lowest value of initial URDL has a relatively low rate of positive $\triangle U R C L$. This indicates that integrating urban-rural development needs a higher socioeconomic level. A region possessing fast socioeconomic change would also experience deterioration of the urban-rural relationship if there is a lack of adequate simulating policy to promote the development of agriculture and rural areas. Thus, it would be essential for central and local government to coordinate urban-rural development based on regional development status.

\section{Discussion and conclusion}

Emphasis on the importance of the factors gathering effect has led strategists and policy makers to promote economic development and urban transition. Rural areas are generally ignored despite an ongoing commitment to the concern with the food security, rural development, and the alleviation of rural poverty in the developing country (McGee, 2008). This investigation measures China's urban-rural development transformation (URDT) by establishing a three-dimension indicator system, including the urban-rural development level (URDL), the urban-rural structure level (URSL), and the urban-rural coordination level (URCL). The spatiotemporal characteristics of China's URDT from 1990 to 2010 were analyzed. The findings show that China has experienced drastic urban-rural development transformation characterized by the growth of urban-rural socioeconomic level, structural level and the fluctuation of its relationship. The estimated indicator system plays an important role in analyzing the spatiotemporal characteristics and interrelationships of China's URDT. This has helped to determine how the regional development status and characteristics promote urban-rural transformation in the context of fast industrialization, urbanization and accelerated globalization.

Influenced by various factors such as socioeconomic conditions and policies, China's URDL, URSL and URCL present different spatial patterns. The value of URDL and URSL show a gradient declining pattern from east to west. And some clusters of cities and regions of abundant energy and resource in western China have higher value as well. The higher value of URCL is located in southeastern and central China. According to the changes of URDT between 1990 and $2010,67.3 \%$ of prefectural cities have worsened the urban-rural relationship with the decline of URCL. These regions are largely distributed due to the lack of a good balance between urban and rural areas in transitional China. By further analysis of the mathematical statistical features of URDT, the internal mechanism was identified. The results show that urban-rural structures are deeply influenced by regional economic level. Economic level and its growth are the bases for integrating urban-rural development. The results of correlation analysis between initial condition and the changes of sub-index suggest that it needs a certain initial economic level to promote coordinated urban-rural development as well as moderate changes of URDL and URSL. However, urban-rural relationship of China is beyond the scope of the level of economy and structure and their changes. The China's urban-rural dual institution, city-centered urbanization and land finance contribute to the relationship.

In transitional China as the biggest developing socialist country in the world, the economic development and evolution of the urban-rural relationships are more complex. Integrating urban and rural development in China faces more severe obstacles. The first is a poor relationship between population and natural resources. China confronts with the deficiency of water resource, cultivated land and other resources per capita, whose mismatches on space magnify the problems and constrict the process of URDT in many regions. That poses challenges for the need among grain security, urban expansion and economic growth. The second is traditional economic growth model with policy prior to industry and fast citycentered urbanization. Even though China has achieved fast economic growth and unique urbanization road, it has exacerbated urban-rural dual economy, a rural brain-drain and the loss of rural collective land and promoted overdependence on land finance as
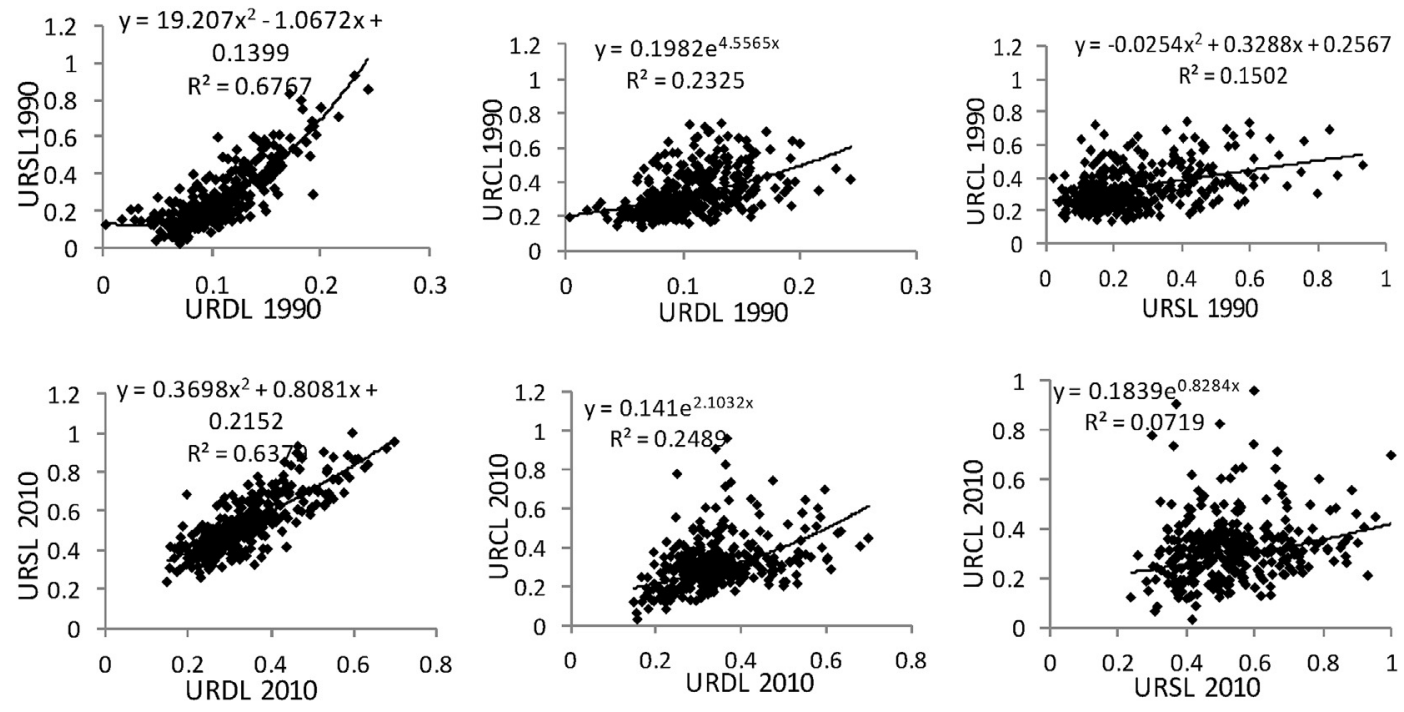

Fig. 5. The relationship among the URDL, URSL and URCL. 

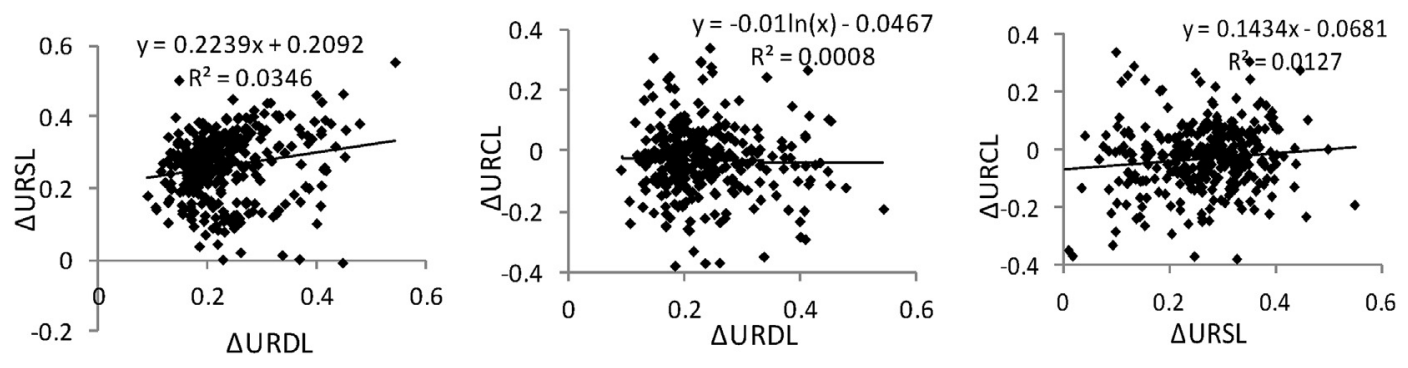

Fig. 6. The relationship among the changes of URDL, URSL and URCL between 1990 and 2010.

well (Wang, Hui, Choguill, \& Jia, 2015). In addition, the rural migrant workers face formidable institutional, economic, cultural and social barriers in the urban society that renders them second class citizens (Wang \& Fan, 2012; Wong, Li, \& Song, 2007). The third is visible interregional inequality. In China, interregional inequality has been long-existed (Fujita \& Hu, 2001), and has been rising, especially between more highly developed eastern region and lagging central and western regions (Li \& Wei, 2010). This regional disparity is confirmed by the URDT shown in Fig. 2. Inevitably, the dynamic of URDT in different regions are diverse. In terms of rural China, they take different transitional pattern. The agricultural plain region and mountainous region have experienced population migration and rural hollowing (Liu, Yang, \& Li, 2013) and, to the contrary, some rural areas around big cities have taken on rural gentrification (He, Qian, Xu, \& Liu, 2012).

The Chinese Government prioritized the urban-rural integration strategy and put building a new socialistic countryside as an important impetus to this strategy after the 16th CPC National Congresses (Long, Liu, Li, \& Chen, 2010). However, the gap between urban and rural areas has historically been wide, and this widened. To better guide the process of urbanization, China's National Development and Reform Commission put forward the "National New-type Urbanization Plan (2014-2020)" in 2014. It aims to refine the existing model of urbanization centered in people urbanization. Though the plan makes an important step, the effectiveness of differentiated household registering, problems about fast urbanization of rural land, and the reform of local government finance are not answered (Wang et al., 2015). How to promote urban and rural development equally under the background of interregional factor mobility and regional disparity of the status and dynamic of URDT is beyond the scope of the plan. According to the result of the multidimensions of URDT, the government should recognize the evolutionary characteristics of both regions and urban-rural areas. It's better to take interregional and urban-rural relationship into unification consideration with macroscopic regional regulation, urban-rural coordinated governance and village-town selfmanagement.

During the progress of urban-rural development transformation, the interaction and equal development right between urban and rural areas should be guaranteed and focused on. It's of importance to make overall arrangements of population mobility, industry transfer, land right and land use change, especially for the adjustment of land-use policies (Liu, Fang, \& Li, 2014). Thus, rural areas can improve self development capacity. With the interregional disparity and the trend of large numbers of rural people migrating to big cities and coastal regions, the central and local government should make suitable supporting policies aimed at various URDT characteristics. In developed areas, it's more suitable to build urban-rural integrating areas in the way of city clusters or city function regions and make more inclusive development for immigrants not only from rural areas surrounding big cites but also from central and western China. Rural areas make economic development and spatial restructuring based on industry cooperation and urban radiating. In the fragile ecological area, such as the loess plateau area in China, it's more considerable to explore urbanization model of a few medium cities and towns based on resources carrying capacity and develop more sustainable economy based on the relationship between the human and physical condition. And more importantly, the development environment for human capital should be improved. Institutions play a significant role in economic development (North, 1990), therefore, the central government should make the targeting supporting policies to simulate bottom-up development of underdeveloped areas in Central and Western China, except for the general transfer payment and infrastructure construction. Given the nature of regional inequalities and the dynamic characters of URDT, improving urban-rural development policies aimed at different kinds of URDT might be the most effective way to shape more coordinated urban-rural development. The layout and implementation of these policies will enable healthy urbanization and rural development in transitional China.

\section{Acknowledgements}

This work was supported by the National Natural Science Foundation of China (Grant Nos. 41130748) and the National Key Technology R\&D Program of China (Grant No. 2014BAL01B01).

\section{References}

Antrop, M. (2004). Landscape change and the urbanization progress in Europe Landscape and Urban Planning, 67, 9-26.

Chen, M. X., Zhang, H., Liu, W. D., \& Zhang, W. Z. (2014). The global pattern of urbanization and economic growth: evidence from the last three decades. PLoS One, 9(8), 1-15.

Douglass, M. (1998). A regional network strategy for reciprocal rural-urban linkages. Third World Planning Review, 20(1), 1-33.

Fujita, M., \& Hu, D. (2001). Regional disparity in China 1985-1994: the effects of globalization and economic liberalization. Regional Science, 35, 3-37.

He, S. J., Qian, J. X., Xu, Y. X., \& Liu, B. (2012). Spatial-temporal evolution of rural gentrification amidst rapid urbanization: a case study of Xiaozhou village, Guangzhou. Acta Geographica Sinica, 67(8), 1044-1055 (in Chinese).

Lewis, W. A. (1954). Economic development with unlimited supplies of labor. The Manchester School of Economics and Social Studies, 22, 139-191.

Li, Y. H., Chen, C., Wang, Y. F., \& Liu, Y. S. (2014). Urban-rural transformation and farmland conversion in China: the application of the environmental Kuznets Curve. Journal of Rural Studies, 36, 311-317.

Li, Y. H., \& Hu, Z. C. (2015). Approaching integrated urban-rural development in China: the changing institutional roles. Sustainability, 7, 7031-7048.

Li, Y. H., Li, Y. R., Hans, W., \& Liu, Y. S. (2015). Urban-rural transformation in relation to cultivated land conversion in China: implications for optimizing land use and balanced regional development. Land Use Policy, 47, 218-224.

Li, T. T., Long, H. L., Liu, Y. Q., \& Tu, S. S. (2015). Multi-scale analysis of rural housing land transition under China's rapid urbanization: the case of Bohai Rim. Habitat International, 48, 227-238.

Li, Y. C., Wang, X. P., Zhu, Q. S., \& Zhao, H. (2014). Assessing the spatial and temporal differences in the impacts of factor allocation and urbanization on urban-rural income disparity in China, 2004-2010. Habitat International, 42, 76-82.

Li, Y. R., \& Wei, Y. H. D. (2010). The spatial-temporal hierarchy of regional inequality of China. Applied Geography, 20, 303-316.

Li, Y. H., Zhang, Z. H., Hans, W., \& Liu, Y. S. (2015). Rural household income in 
transitional China: spatial-temporal disparity and its interpretation. China: An International Journal, 13(2), 151-168.

Li, Y. H., Zhang, Z. H., \& Liu, Y. S. (2013). Spatial-temporal contrasts in integrated urban-rural development in China, 1990-2010. China: An international Journal, 11(3), 1-19.

Lin, G. C. S. (2001). Evolving spatial form of urban-rural interaction in the Pearl River Delta, China. The Professional Geographer, 53(1), 56-70.

Lin, G. C. S. (2007). Reproducing spaces of Chinese urbanization: new city-based and land-centered urban transformation. Urban Studies, 44(9), 1827-1855.

Lipton, M. (1993). Urban bias: of consequences, classes and causality. Journal of Development Studies, 4(29), 229-258.

Liu, Y. S., Fang, F., \& Li, Y. H. (2014). Key issues of land use in China and implications for policy making. Land Use Policy, 40, 6-12.

Liu, Y. S., Hu, Z. C., \& Li, Y. H. (2014). Process and cause of urban-rural development transformation in the Bohai Rim region, China. Journal of Geographical Science, 24(6), 1147-1160.

Liu, J. Y., Kuang, W. H., Zhang, Z. X., Xu, X. L., Qin, Y. W., Ning, J., et al. (2014). Spatialtemporal characteristics, patterns, and causes of land-use changes in China since the late 1980s. Journal of Geographical Sciences, 24(2), 195-210.

Liu, Y. S., Liu, Y., Chen, Y. F., \& Long, H. L. (2010). The process and driving forces of rural hollowing in China under rapid urbanization. Journal of Geographical Sciences, 20(6), 876-888.

Liu, Y. S., Lu, S. S., \& Chen, Y. F. (2013). Spatio-temporal change of urban-rura equalized development patterns in China and its driving factors. Journal of Rural Studies, 32, 320-330.

Liu, Y. S., Yang, R., \& Li, Y. H. (2013). Potential of land consolidation of hollowed villages under different urbanization scenarios in China. Journal of Geographica Sciences, 23(3), 503-512.

Long, H. L., Liu, Y. Q., Hou, X. G., Li, T. T., \& Li, Y. R. (2014). Effects of land use transitions due to rapid urbanization on ecosystem services: implications for urban planning in the new developing area of China. Habitat International, 44 $536-544$.

Long, H. L., Liu, Y. S., Li, X. B., \& Chen, Y. F. (2010). Building new countryside in China: a geographical perspective. Land Use Policy, 27, 457-470.

Long, H. L., Zou, J., \& Liu, Y. S. (2009). Differentiation of rural development driven by industrialization and urbanization in eastern coastal China. Habitat International, 33, 454-462.

Long, H. L., Zou, J., Pykett, J., \& Li, Y. R. (2011). Analysis of rural transformation development in China since the turn of the new millennium. Applied Geography 31, 1094-1105.

Martins, P., \& Romans, J. (2005). Transitions in a globalising world. Future, 37,
1133-1144.

McGee, T. C. (1989). Urbanisai or Kotadesasi? Evolving patterns of urbanization in Asia. In F. J. Costa, et al. (Eds.), Urbanization in Asia: Spatial dimensions and policy issues (pp. 93-108). Honolulu: University of Hawaii Press.

McGee, T. G. (2008). Managing the rural-urban transformation in East Asia in the 21st century. Sustainablility Science, 3(1), 155-167.

North, D. C. (1990). Institutions, institutional change and economic performance. New York: Cambridge University Press.

Ord, J. K., \& Getis, A. (1995). Local spatial autocorrelation statistics: distributional issues and an application. Geographical Analysis, 27(4), 286-306.

Siciliano, G. (2012). Urbanization strategies, rural development and land use changes in China: a multiple-level integrated assessment. Land Use Policy, 29, 165-178.

Tacoli, C. (1998). Rural-urban interactions: a guide to the literature. Environment and Urbanization, 10(1), 147-166

Terry, S., Yue, X. M., Vjörn, G., \& Li, S. (2007). The urban-rural income gap and inequality in China. Review of Income and Wealth, 53(1), 93-126.

Todaro, M. P. (1969). A model of labor migration and urban unemployment in less development countries. American Economic Review, 59(3), 138-148.

Wang, W. W., \& Fan, C. C. (2012). Migrant workers' integration in urban China: experiences in employment, social adaptation, and self-identity. Eurasian $\mathrm{Ge}$ ography and Economics, 53(6), 731-749.

Wang, X. R., Hui, E. C. M., Choguill, C., \& Jia, S. H. (2015). The new urbanization policy in China: which way forward? Habitat International, 47, 279-284.

Wei, Y. H. D. (2001). Decentralization, marketization, and globalization: the triple processes underlying regional development in China. Asian Geographer, 20(1-2), 7-23.

Wei, Y. H. D. (2015). Zone fever, project fever: economic transition, development policy, and urban expansion in China. Geographical Review, 105(2), 156-177.

Wong, D. F. K., Li, C. Y., \& Song, H. X. (2007). Rural migrant workers in urban China: living a marginalized life. International Social Welfare, 16, 32-40.

Woods, M. (2009). Rural geography: blurring boundaries and making connections. Progress in Human Geography, 33(6), 849-858.

Yu, A. T. W., Wu, Y. Z., Zheng, B. B., Zhang, X. L., \& Shen, L. Y. (2014). Identifying risk factors of urban-rural conflict in urbanization: a case of China. Habitat International, 44, 177-185.

Zhang, P. Y. (2008). Revitalizing old industrial base of Northeast China: process, policy and challenge. Chinese Geographic Science, 18(2), 109-118.

Zou, Z. H., Yun, Y., \& Sun, J. N. (2006). Entropy method for determination of weight of evaluating indicators in fuzzy synthetic evaluation for water quality assessment. Journal of Environmental Sciences, 18(5), 1020-2023. 